\title{
Sediment flux from the Zhoushan Archipelago, eastern China
}

\author{
LI Gaocong ${ }^{1,3}$, "GAO Shu², WANG Yaping ${ }^{1}$, LI Chunyan ${ }^{3}$ \\ 1. Collaborative Innovation Center of South China Sea Studies, Nanjing University, Nanjing 210023, China; \\ 2. State Key Laboratory for Estuarine and Coastal Research, East China Normal University, Shanghai 200062, China; \\ 3. Department of Oceanography and Coastal Sciences, Louisiana State University, Baton Rough 70803, USA
}

\begin{abstract}
Knowledge of the sediment flux derived from different sources is critical for interpreting the sedimentary records associated with large river sedimentary systems. For the Changjiang River system, previous studies hardly focused on the sediment load from the adjacent Zhoushan Archipelago (ZA). Based on four prediction models, aiming to improve the understanding of the sediment load from the $Z A$ during the Holocene, we show that the predicted sediment flux of the ZA ranges from $\sim 0.7$ to $26.5 \mathrm{Mt} \cdot \mathrm{yr}^{-1}$, with an average value of $10.7 \mathrm{Mt} \cdot \mathrm{yr}^{-1}$, and the islands with a relatively large area or high relief contribute greatly to the total flux. This sediment load is an order of magnitude lower than that of the Changjiang River, but it is similar to those of the local small rivers. Located in the core area of the southward dispersal path of the Changjiang River plume, the ZA also influences the sediment transport into Hangzhou Bay and over the Zhejiang-Fujian coastal seas. On the Holocene temporal scale, e.g., for the period from 6 ka BP to 2 ka BP, the sediments discharged from the ZA had a considerable effect on the shelf sedimentary system. This study provides evidence for an important role an archipelago can play in terms of sediment supply and transport in coastal and inner continental shelf regions.
\end{abstract}

Keywords: sediment load; sedimentary systems; Holocene; archipelago environment; eastern China

\section{Introduction}

Grouped continental shelf islands (i.e., an archipelago) are located between the mainland and the adjacent deep-sea regions. They were once connected to the mainland during low sea level periods of the Quaternary ice ages (Whittaker and Fernández-Palacios, 2007). They are of importance not only for the studies of paleogeography (Ogasawara, 1994; Bover et al., 2008) and biogeographic evolution (Stankowski et al., 2014; Blackburn et al., 2013), but

Received: 2017-05-09 Accepted: 2017-08-25

Foundation: National Natural Science Foundation of China, No.41530962, No.41625021; The National Basic Research Program of China, No.2013CB956500; Natural Science Foundation of Jiangsu Province, No.BK20130056

Author: Li Gaocong (1987-), PhD Candidate, specialized in estuarine and coastal sciences. E-mail: ligaocong2013@163.com "Corresponding author: Gao Shu (1956-), Professor, E-mail: sgao@sklec.ecnu.edu.cn 
also in many other aspects such as sediment supply (Milliman and Syvitski, 1992; Milliman et al., 1999), fishery resources (Fukuta et al., 2017; Jackson et al., 2014), habitat (Carvajal-Endara et al., 2017), tourism (Baldacchino, 2016; Kurniawan et al., 2016), and territorial sovereignty (Mountz, 2015; Palestini, 2016). In terms of sediment dispersal and accumulation, they contribute to the overall shelf deposits which are otherwise only linked with the mainland's rivers. In such places, the huge sedimentary systems consisting of river deltas and distal mud deposits (Gao et al., 2015; Hanebuth et al., 2015) are best records of past climate, environment and ecosystem changes (Bianchi and Allison, 2009; Gao and Collins, 2014; Gao et al., 2016), but the knowledge of sediment flux from the islands in addition to the mainland input (Syvitski, 2003) is crucial to an appropriate interpretation of the sedimentary records.

Regarding the above mentioned situations, the Zhoushan Archipelago (ZA) in eastern China represents a typical example. For the Holocene period, the Changjiang River sedimentary system (CRSS) has been formed on the inner continental shelf of the East China Sea, including the Changjiang River delta, Hangzhou Bay mud deposits, and Zhejiang-Fujian inner shelf mud deposits (Liu et al., 2006; Xu et al., 2012; Gao, 2013; Gao et al., 2015). The ZA, located to the south of the Changjiang River mouth, lies over the corridor of the southward dispersal of the Changjiang Diluted Water (CDW), and in between the Hangzhou Bay and the East China Sea (ECS) (Hu et al., 2009). Apparently, the intensity of sediment transport associated with the CDW and the cross-shelf transport between the Hangzhou Bay and the ECS is to some degree affected by the ZA.

A number of studies have been carried out on the role of terrestrial sediment supply from the Changiiang River (Liu et al., 2006; Xu et al., 2012) and small coastal rivers (Chen et al., 1990; Gao, 2013; Gao and Collins, 2014). However, there has not yet been a holistic analysis on the role played by the ZA. Previous investigations are mainly focused either on the grain size and chemical characteristics of the surficial sediment (Yan et al., 1981; Sha, 2007; Liu et al., 2012), or on the processes of sediment transport, resuspension and deposition around the ZA (Su and Wang, 1989; Hu et al., 2009; Xie et al., 2017). The major obstacle to evaluate the sediment load from the ZA is the lack of gauging station records on these islands. However, previous studies (Milliman and Syvitski, 1992; Syvitski et al., 2003; Milliman and Farnsworth, 2013; Gao and Collins, 2014) have shown that river sediment flux depends upon the catchment characteristics, e.g., drainage area, lithology, tectonic movement, relief, rainfall, air temperature and anthropogenic activities. Here, we use four existing models to calculate the sediment flux, using a previously published islands' topography dataset of the ZA (Xia, 2014). On such a basis, we discuss the influence of the sedimentary materials derived from the ZA on the deposition of the CRSS during the Holocene.

\section{Regional setting}

The ZA is located in the northwest of the East China Sea, south of the Changjiang Estuary and east of the Hangzhou Bay (Figure 1a). It is the biggest archipelago in China, consisting of 1814 islands with a total surface area of $1331 \mathrm{~km}^{2}$ and a shoreline length of $2388 \mathrm{~km}$ (Xia, 2014). These islands are aligned in a northeast-southwest orientation. The islands in the south are larger and higher than those in the north (Figure 1b). The Zhoushan Island is the largest in this region, with a surface area of $\sim 491 \mathrm{~km}^{2}$, and the Taohua Island is the highest, 
with a maximum elevation of $\sim 545 \mathrm{~m}$ above sea level (Xia, 2014).

The region is characterized by a subtropical monsoon climate: northerly winds prevail in winter but southerly winds are predominant in summer. The annual average air temperature is $16^{\circ} \mathrm{C}$, and on average the annual rainfall exceeds $1200 \mathrm{~mm}$ (Xia, 2014). The waves are generally moderate except for the summer time when the region is influenced by typhoons, and the tides are mainly semi-diurnal (Gao et al., 2016). The ZA is in the convergence zone of low salinity and high nutrients waters from the Zhejiang coast, cool and medium salinity and relative high nutrients water from the Yellow Sea, and high salinity and low nutrients waters from the Taiwan Warm Current (TWC) (Wang and Yu, 1992; Zhang et al., 2007). The mixing of cool and warm waters, together with the mixing of low and high salinity and nutrient content waters, provide favorable conditions of reproduction, growth, feeding, and overwintering for various fishes (Wang et al., 2016). Consequently, the ZA and its surrounding areas form the largest fishing ground in China (Liu et al., 1991), although at the moment the Zhoushan Fishing Ground is experiencing reductions in fishery catch due to long-term overfishing (Wang and Yu, 1992; Wang et al., 2016).
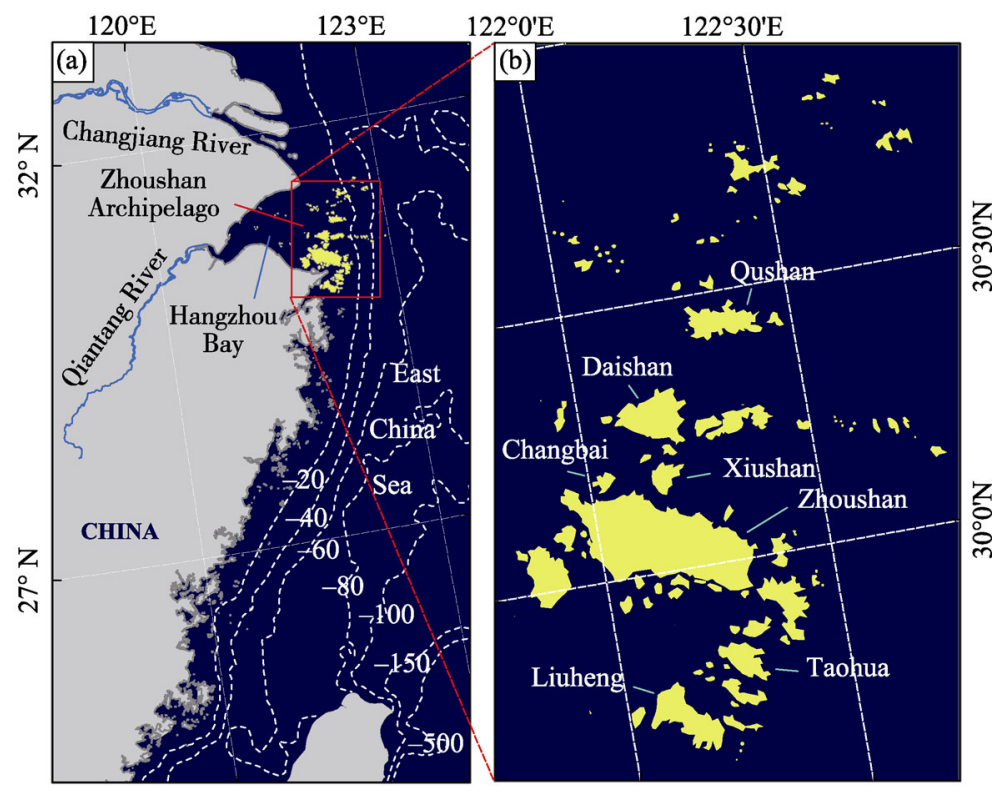

Figure 1 Location of the study area (a) and the major islands of the Zhoushan Archipelago (b)

\section{Methods}

\subsection{Data source}

The dataset contained in Xia's study (2014) is used in the present study. The islands' area ranges from $\sim 4$ to $490,913,910 \mathrm{~m}^{2}$, with an average area of $734,495 \mathrm{~m}^{2}$. For these islands, 2 , 18 and 60 islands have their areas of more than $10^{8}, 10^{7}$, and $10^{6} \mathrm{~m}^{2}$, accounting for $44.87 \%$, $86.02 \%$ and $95.69 \%$ of the total area of the ZA, respectively (Figure 2). Among these, 304 islands are without maximum relief data, and their total area is $401,690 \mathrm{~m}^{2}$, ranging between 10 and $100,710 \mathrm{~m}^{2}$, which occupied about $0.03 \%$ of the total area of the ZA. For conven- 
ience, the maximum relief of these islands is assumed to be $17.7 \mathrm{~m}$, which is the same as the average value for the islands with the same land area range, based on the dataset. Thus, for all of the islands, the maximum relief ranges from 0.4 to $544.7 \mathrm{~m}$, with an average of $27.7 \mathrm{~m}$. Meanwhile, 2, 23, 80 and 210 islands have a maximum relief larger than 500, 200, 100, and $50 \mathrm{~m}$, respectively (Figure 2). Volcanic rocks are widely distributed in the ZA, accounting for about $80 \%$ of the islands' area, of which extrusive rocks (mainly composed of lava and volcanic clastic rocks) are most widely distributed, followed by crypto volcanic rocks (mainly composed of shallow felsophyre and dacite-porphyrite) (Sha, 2007). Meanwhile, intrusive rocks account for $14 \%$ of the areal coverage, and are mainly composed of quartz-diorite, quartz-monzobiorite, monzonitic-granite and granite (Sha, 2007).

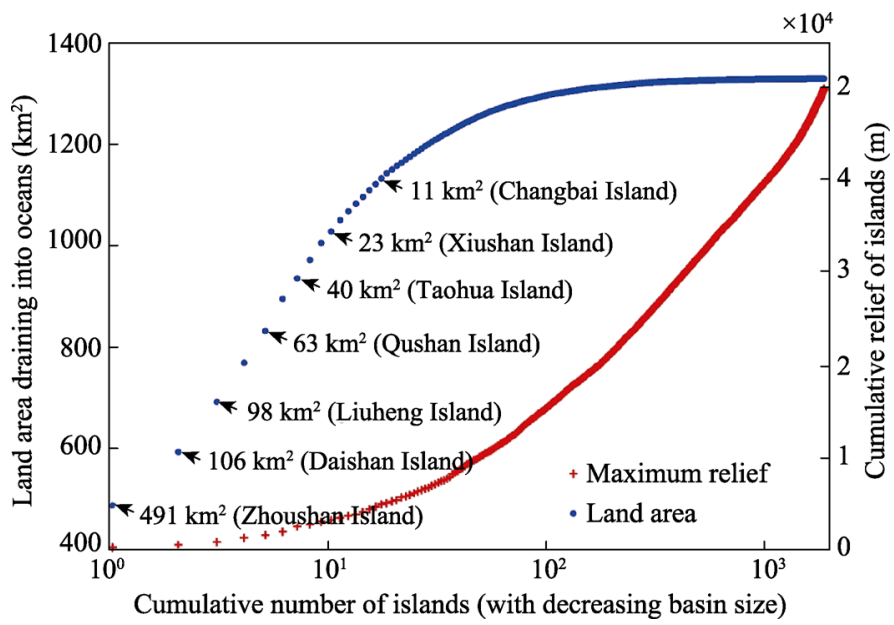

Figure 2 Cumulative area and maximum relief of 1814 islands of the Zhoushan Archipelago in relation to drainage basin size

\subsection{Analytical methods}

Based on the database of hundreds of globally distributed rivers, a close correlation between sediment load and parameter(s) of basin has been identified. Milliman and Syvitski (1992) pointed out that there is a strong correlation between sediment load and catchment area. Mulder and Syvitski (1996) improved the sediment load-catchment area curve by introducing the maximum relief into the relationship. With considerations of climate zones, Syvitski et al. (2003) suggested that the basin air temperature must affect a river's sediment flux, which should be also included in the model. Furthermore, Syvitski and Milliman (2007) took into account of the factor of human activities, which led to the establishment of a global predictor of sediment load, i.e., the BQART Model. In this study, the above four models were used to predict the sediment flux of the islands in the ZA. The output values of the four models play a role for mutual validation to overcome the shortcoming of the lack of gauging station records.

For small islands, the maximum reliefs of the different basins are relatively consistent, and the sum of the sediment load of the individual islands is almost equal to a basin with the same maximum relief and catchment area. Therefore, it was assumed that each island in the ZA can be regarded as a single river basin.

In the model (MS1992) proposed by Milliman and Syvitski (1992), sediment load $\left(Q_{S}\right.$, 
$\left.\mathrm{Mt} \cdot \mathrm{yr}^{-1}\right)$ is a piecewise function of basin area $\left(A, \mathrm{M} \mathrm{km}^{2}\right)$, depending on the maximum elevation range $(R, \mathrm{~m})$ of the river basin:

$$
Q_{S}=\left\{\begin{array}{cl}
12 A^{0.42}, & \text { if } 500 \leqslant R<1000 \\
8 A^{0.66}, & \text { if } 100 \leqslant R<500 \\
A^{0.64}, & \text { if } R<100
\end{array}\right.
$$

In the Mulder and Syvitski (1996) model (MS1996), $Q_{S}$ is an exponential function of basin area $\left(A, \mathrm{~km}^{2}\right)$ and maximum elevation $(R, \mathrm{~m})$ :

$$
Q_{S}=\alpha 10^{(0.4058 \log (A)+1.2789 \log (R)-3.679)}
$$

where $\alpha$ is a constant $(0.0315)$ due to unit conversion from $\mathrm{kg} \cdot \mathrm{s}^{-1}$ to $\mathrm{Mt} \cdot \mathrm{yr}{ }^{-1}$.

In the Syvitski et al. (2003) model (S2003), $Q_{S}$ is a function of average discharge, maximum relief and basin-average temperature:

$$
\begin{gathered}
Q=\left\{\begin{array}{l}
0.039 A^{0.85}, \text { if lat. }>30^{\circ} \mathrm{N}, T>0^{\circ} \mathrm{C} \\
0.53 A^{0.70}, \text { if } 0 \leqslant \text { lat. } \leqslant 30^{\circ} \mathrm{N}, T>0^{\circ} \mathrm{C}
\end{array}\right. \\
Q_{S}=\left\{\begin{array}{l}
1.1 \times 10^{-4} \alpha A^{0.53} A^{1.1} e^{0.06 T}, \text { if lat. }>30^{\circ} \mathrm{N}, T>0^{\circ} \mathrm{C} \\
2 \alpha A^{0.45} R^{0.57} e^{-0.09 T}, \text { if } 0 \leqslant \text { lat. } \leqslant 30^{\circ} \mathrm{N}, T>0^{\circ} \mathrm{C}
\end{array}\right.
\end{gathered}
$$

where $Q$ is average discharge $\left(\mathrm{m}^{3} \cdot \mathrm{s}^{-1}\right), \alpha=0.0315$ is a constant of proportionality, $A$ is drainage basin area $\left(\mathrm{km}^{2}\right), T$ is basin-average temperature $\left(16.3^{\circ} \mathrm{C}\right)$, and $R$ is maximum relief from sea level to the mountain top (m).

Finally, in the Syvitski and Milliman (2007) model (SM2007), $Q_{S}$ is estimated based upon geomorphic and tectonic influences (basin area and relief), geography (temperature, runoff), geology (lithology, ice cover), and human activities (reservoir trapping, soil erosion):

$$
\begin{gathered}
Q=0.075 A^{0.8} \\
Q_{S}=\omega B Q^{0.31} A^{0.5} R T
\end{gathered}
$$

where $Q$ is fluvial discharge $\left(\mathrm{m}^{3} \cdot \mathrm{s}^{-1}\right), A$ is drainage area $\left(\mathrm{km}^{2}\right)$, and $\omega=0.0006$ is a constant of proportionality; $B=I L\left(1-T_{E}\right) E_{h}$ accounts for geological and land use factors; $I$ is glacier erosion factor ( 1 in this case); $L$ is an average basin-wide lithology factor; and $T_{E}$ and $E_{h}$ account respectively for the trapping efficiency of lakes and man-made reservoirs and human-influenced soil erosion factor, which we assumed to cancel out (Syvitski and Milliman 2007; Nienhuis et al., 2015). Since the basins of the ZA are mainly composed of volcanic rocks (Sha, 2007), we took $L=1$ on the basis of Syvitski and Milliman (2007), $R$ as the relief $(\mathrm{km})$ and $T=16.3$ as the basin average temperature, for the ZA.

\section{Results}

Based on the predictive models, $Q_{S}$ values for each island in the ZA have been derived, and their statistical characteristics are shown in Figures 3-5. The order of magnitude for $Q_{S}$ varies from model to model. Among them, the MS1992 output has the least range, from $10^{2}$ to $10^{5}$ $\mathrm{t} \cdot \mathrm{yr}^{-1}$, and those of MS1996 and SM2007 have relatively wider ranges, with magnitudes from $10^{0}$ to $10^{5} \mathrm{t} \cdot \mathrm{yr}^{-1}$. The S2003 output has the widest range, with magnitudes from $10^{0}$ to $10^{6} \mathrm{t} \cdot \mathrm{yr}^{-1}$.

The different orders of magnitude for $Q_{S}$ showed significant variations among the four 
models. When using the model of MS1992, in terms of the highest frequency of occurrence, 1464 islands have the $Q_{S}$ value with the order of magnitude of $10^{3} \mathrm{t}^{\cdot} \mathrm{yr}^{-1}$, whereas for the models of MS1996, S2003 and SM2007, 882, 714 and 1463 islands have the values with the orders of magnitude of $10^{1}, 10^{0}$ and $10^{0} \mathrm{t}^{\circ} \mathrm{yr}^{-1}$, respectively (Figure 3a). Similarly, the magnitude of a secondary highest frequency of occurrence is $10^{4} \mathrm{t}^{\mathrm{yr}} \mathrm{yr}^{-1}$ for MS1992, associated with 262 islands, whilst those for the latter three models are $10^{0}, 10^{3}$ and $10^{1} \mathrm{t} \cdot \mathrm{yr}^{-1}$, associated with 533, 428 and 233 islands, respectively (Figure 3a).

In terms of the relative importance, the islands associated with the sediment load that has an order of magnitude of $10^{5} \mathrm{t}^{\cdot} \mathrm{yr}^{-1}$ contribute $42.29 \%$ of the total flux, according to the model of S2003. However, for the model of MS1992, MS1996 and SM2007, the islands associated with a magnitude of $10^{4} \mathrm{t}^{\mathrm{yr}} \mathrm{yr}^{-1}$ are the most important, which account for $44.44 \%$, $53.52 \%$ and $42.35 \%$ of the total flux, respectively (Figure $3 \mathrm{~b}$ ). In general, for all the models, there are only a few islands that have a $Q_{S}$ magnitude of $10^{5} \mathrm{t}^{\cdot} \mathrm{yr}^{-1}$ or higher, but their contribution accounts for $16 \%-34.80 \%$ of the total flux.
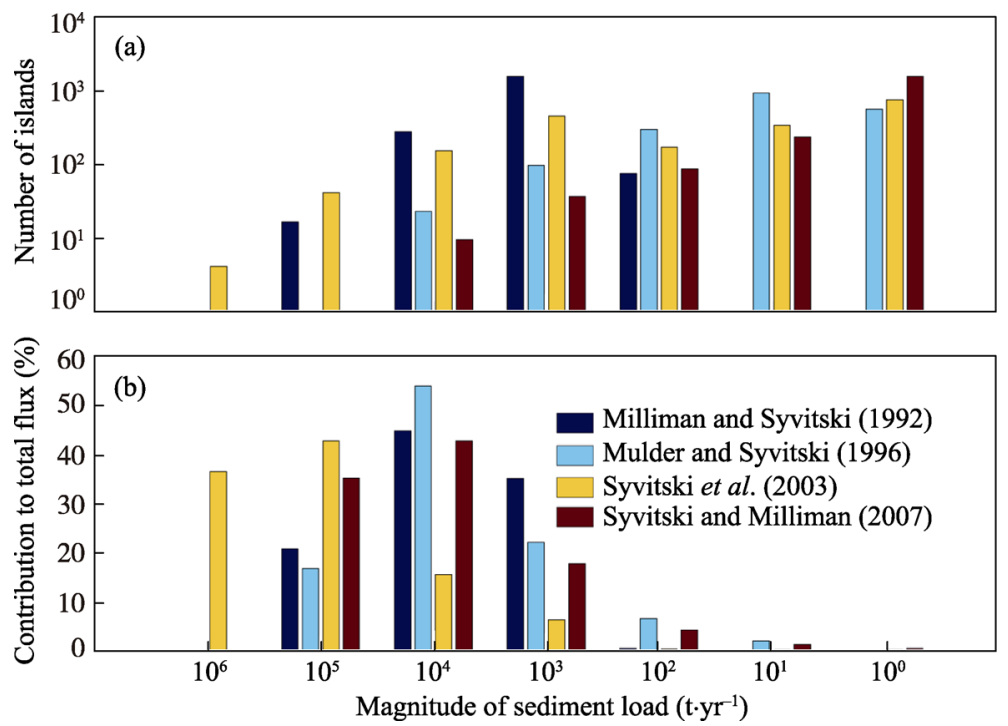

Figure 3 Statistical characteristics of the sediment load $\left(Q_{S}\right)$ data: (a) the number of the islands associated with different magnitudes of sediment load; and (b) the relationship between the island category represented by the sediment load and the contribution to the total sediment discharge (in percentage) made by the different island categories

The magnitude of $Q_{S}$ is closely related to the topographic characteristics (area or/and maximum relief) of the islands (Figure 4). The regional difference in $Q_{S}$ is obvious: for the S2003 model, the $Q_{S}$ values are larger (i.e., $10^{4}-10^{6} \mathrm{t} \cdot \mathrm{yr}^{-1}$ ) to the south of $30^{\circ} \mathrm{N}$, than those to the north of $30^{\circ} \mathrm{N}$ (i.e., $10^{0}-10^{3} \mathrm{t}^{\mathrm{yr}} \mathrm{yr}^{-1}$ ) (Figure 4e). For the MS1992, MS1996 and SM2007 models, this difference is reduced to some extent (Figures 4c, 4d, and 4f)

In terms of the total sediment flux, the S2013 output $\left(26.5 \mathrm{Mt} \cdot \mathrm{yr}^{-1}\right)$ represents the largest

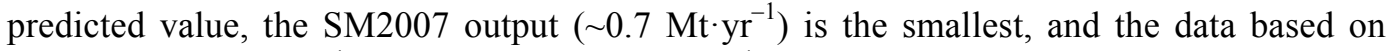
MS1992 (14.4 Mt $\left.\cdot \mathrm{yr}^{-1}\right)$ and MS1996 (1.4 Mt $\left.\cdot \mathrm{yr}^{-1}\right)$ lie in between the two extremes. On average, the sediment flux of the $\mathrm{ZA}$ is around $10.7 \mathrm{Mt} \cdot \mathrm{yr}^{-1}$. Meanwhile, the cumulative $Q_{S}$ curves show rapid increase on the left side (in terms of either basin size or maximum relief (Figure 5), suggesting that the islands with a large basin area or a maximum relief dominate the total flux of the ZA. 

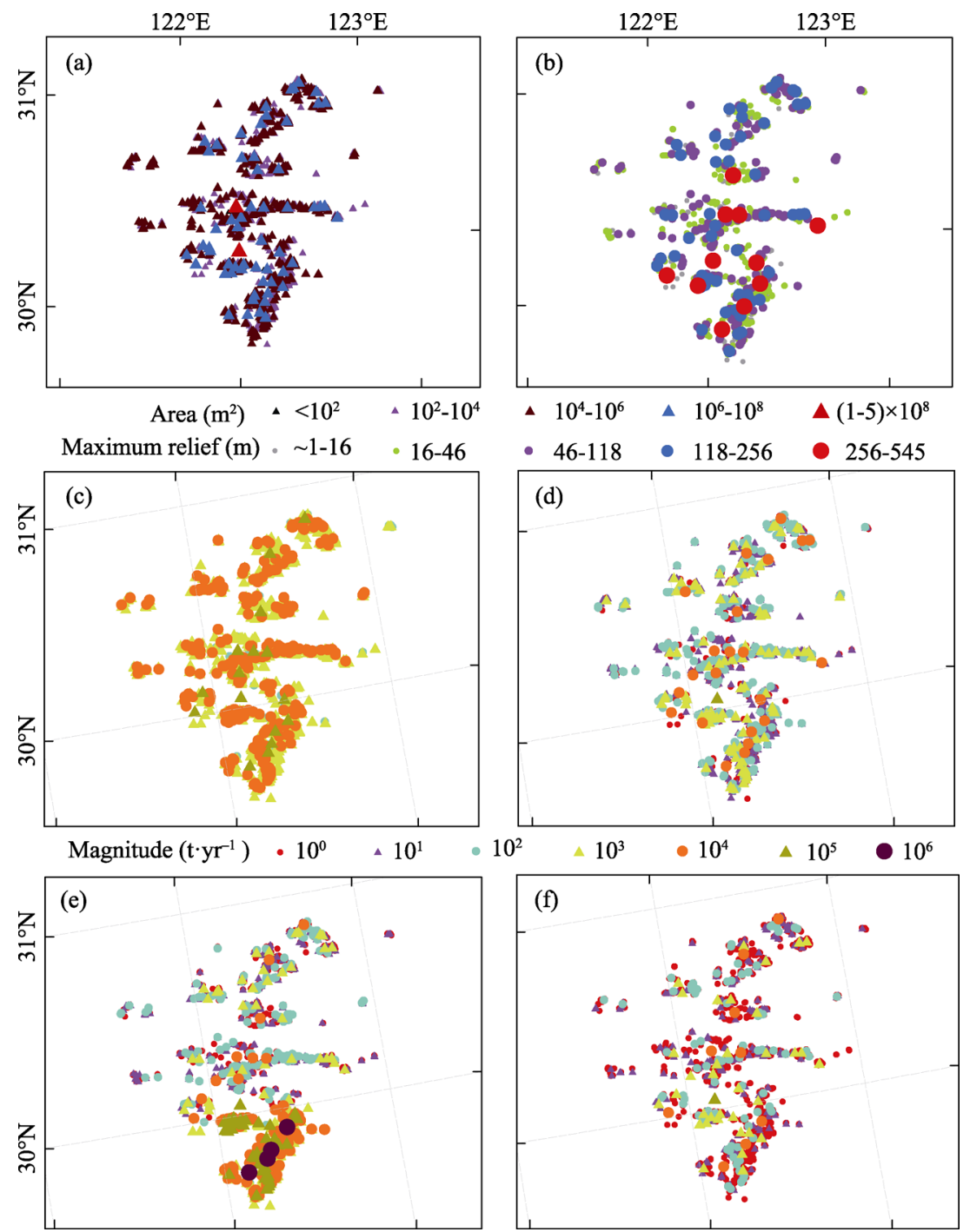

Figure 4 Spatial distribution patterns of island area (a), maximum relief (b), $Q_{S}$ predicted by Milliman and Syvitski (1992) model (c), Mulder and Syvitski (1996) model output (d), Syvitski et al., (2003) model output (e), and Syvitski and Milliman (2007) model output (f)

\section{Discussion}

The information on sediment provenance is fundamental in the interpretations of sedimentary records associated with the Holocene sedimentary systems, especially those of large rivers (Gao et al., 2015). The sedimentary materials supplied by the Changjiang River are the largest source to the CRSS, with a sediment flux of $486 \mathrm{Mt}^{\cdot} \mathrm{yr}^{-1}$ (Milliman et al., 1985) before the building of the many dams in the catchment areas. Compared with the Changjiang River, the sediment supplied by the mountainous rivers along the Zhejiang, Fujian and Taiwan coastlines are also important for the CRSS. In this study, the results from the four models indicate that the $Q_{S}$ values of the ZA range from $\sim 0.7$ to $26.5 \mathrm{Mt}^{\cdot} \cdot \mathrm{yr}^{-1}$, with an average of $10.7 \mathrm{Mt} \cdot \mathrm{yr}^{-1}$. This is at least one order of magnitude lower than those of the Changjiang 

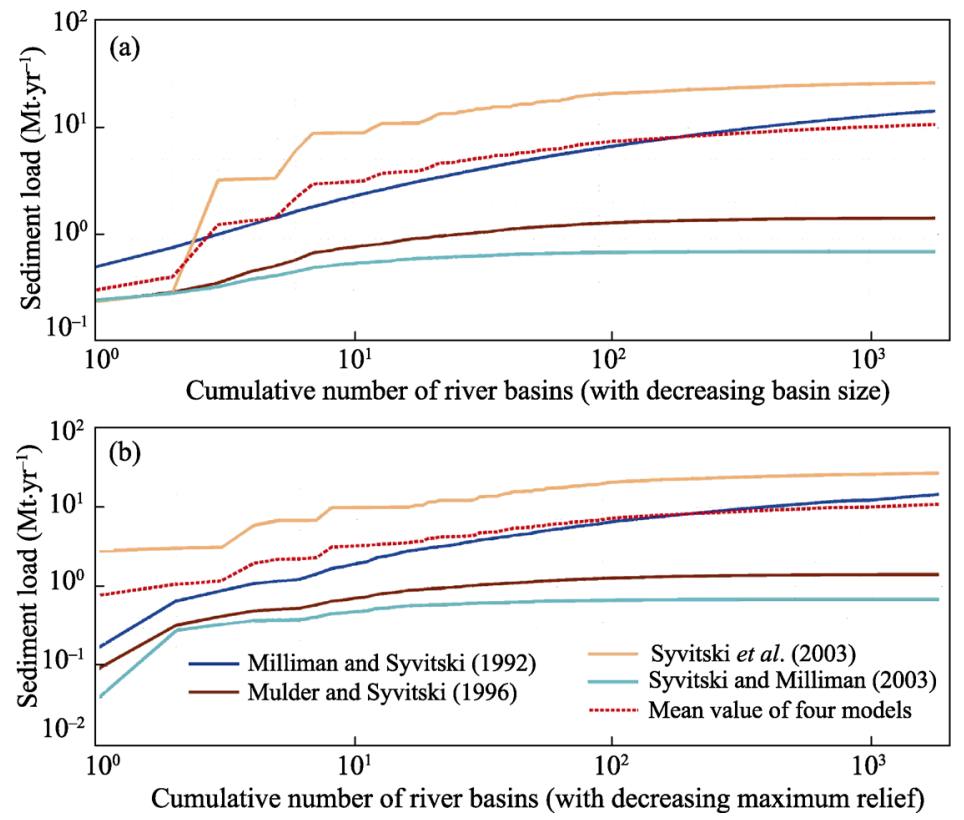

Figure 5 Cumulative sediment load of the Zhoushan Archipelago calculated by the four predictive models

River and the Choshui River of the Taiwan Island (30-60 Mt· $\mathrm{yr}^{-1}$ ) (Liu et al., 2008), but comparable to those of Jiaojiang River $\left(0.8 \mathrm{Mt}^{\cdot} \mathrm{yr}^{-1}\right)$ (Sun and Huang, 1984), Oujiang River (2.7 Mt $\cdot \mathrm{yr}^{-1}$ ), Minjiang River (7.3 Mt $\mathrm{yr}^{-1}$ ) (Compilation Committee of China Bays, 1998),

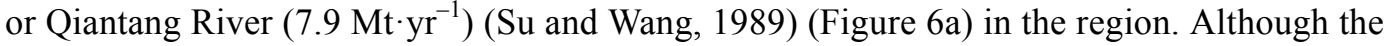
accurate value of this estimate is yet to be verified, there is no doubt that the ZA discharges a considerable amount of sediment into the adjacent shelf waters, both from the drainage basins discharge and/or the erosion of rocky coasts. Thus, more attention should be paid to the evaluation of the ZA sediment input, which is important for understanding any temporal shifts in sediment supply to the CRSS.

A number of publications provide insights into the ZA sediment supply for the adjacent areas. Based on a study on physical and chemical characteristics of the coastal sediments of Putuo Island, Yan et al. (1981) pointed out that here the supertidal, intertidal and even upper part of subtidal areas are mainly composed of gravels, coarse- and fine-grained sands, mostly derived from the erosion of volcanic rocks of this island. A similar result by Li et al. (2002) showed that the weathering products of islands were the main sources of coarse particles of surficial sediments in the Qiqu Archipelago region. Sha (2007) showed that the clastic minerals of the seabed sediments in the ZA sea area are characterized by a quartz-feldsparhornblende-epidote-flakey mineral-metallic mineral group, indicating that the sediments were derived from adjacent rivers and nearby areas. Moreover, Hu et al. (2009) pointed out that the grain size parameters of surficial sediments are obviously affected by the archipelago, and the bottom sediments generally become finer, well sorted and more negatively skewed with the increasing distance to the islands (Figures 7a, 7b, and 7c). For the Hang zhou Bay, the surficial sediments can be classified into three geochemical provinces (Liu et al., 2012). Province I covers the northern Hangzhou Bay, dominated by suspended sediments derived from the Changjiang River. Sediments from Qiantang River dominate 

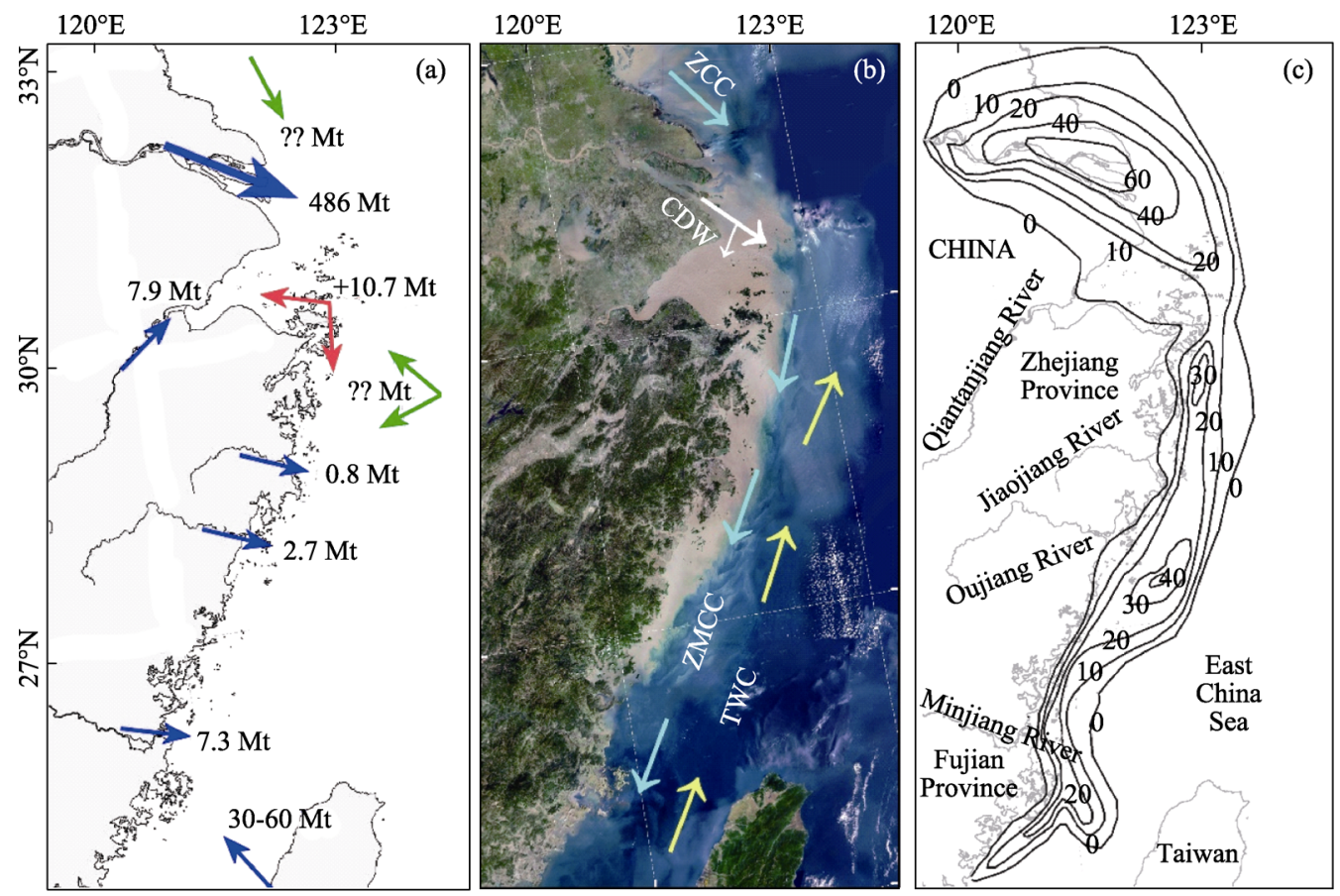

Figure 6 Sediment source and sink patterns of the CRSS: (a) annual sediment supply rates from the various sources; (b) remote sensing imagery (based on Baidu Map (http://map.baidu.com/)), and the major shelf currents (compiled on the basis of Chen (2009)) which affect sediment transport; and (c) isopach map (in meters) of the Changjiang River-dominated deposits formed over the last 7000 years on the inner shelf of the East China Sea (after Liu et al., 2006)

Province II, located in the western Hangzhou Bay. Province III occupies the middle and eastern Hangzhou Bay, which is characterized by relatively high contents of quartz, feldspar and amphibole, and the sediment sources include not only the above two rivers, but also the weathering of the volcanic rocks, i.e., granite and granodiorite. The general pattern is that the coarse sediments derived from the ZA are mainly deposited near the island shorelines, and the fine-grained materials may deposit further away from the shoreline, e.g., in the inner Hangzhou Bay and over the Zhejiang-Fujian coastal seas (Figure 7).

The southward dispersal of fine-grained sediments derived from the Changjiang River contributes to the formation of large areas of mud deposits, in Hangzhou Bay and on the inner shelf off the Zhejiang-Fujian coast (Figure 6). The processes for such southward dispersal are associated with the interaction of tides, waves, the Changjiang Diluted Water (CDW), the China Coastal Current (especially the Zhejiang-Fujian Coastal Currents, ZMCC), winter storms, and the Taiwan Warm Current (TWC) (Su and Wang, 1989; Lin et al., 2005; Liu et al., 2006; Xu et al., 2012) (Figure 6b). Located in the core area of the southward dispersal path of the Changjiang River sediments, the ZA not only supplies additional sediments, but also serves as an obstacle for the sediments to enter Hangzhou Bay and Zhejiang-Fujian coastal seas (Figures 6a, 6b, and 7d). When the suspended sediment plume passes the ZA, the coarse particles is filtered and fine particles may flow through the island areas, a mechanism known as the "archipelago effect" (Hu et al., 2009). Detailed analyses on the sediment budget of the Changjiang River by Wu et al., (2006), Xie et al., (2013), Yang et al., (2015) 

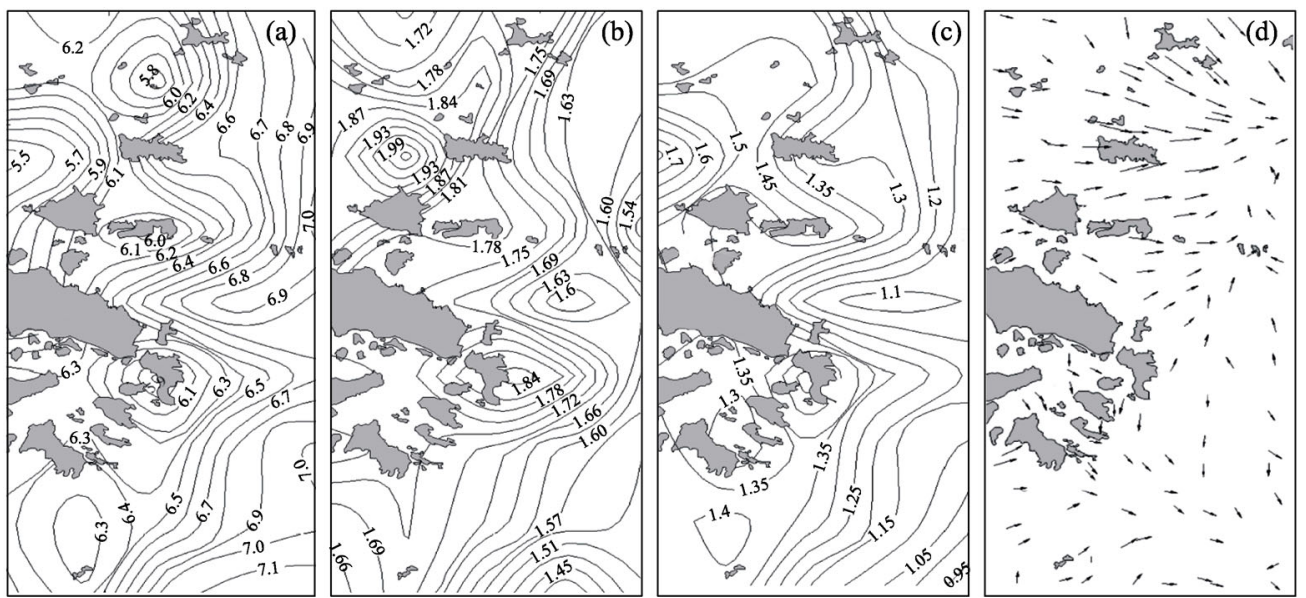

Figure 7 The distribution of mean grain size in $\varphi$ (a), sorting efficient (b), and skewness (c), and sediment transport pathways of sea-bed sediment (d) in the Zhoushan Archipelago sea area (after Hu et al., 2009)

and Xie et al., (2017) indicate that before the 1980s the net sediment flux across the Luchaogang, Hangzhou Bay and Zhoushan transects were 230, 135 and $85 \mathrm{Mt} \mathrm{yr}^{-1}$, respectively. For the last 30 years, however, the effects of human activities, especially the building of the Three Gorges Dam in 2003, on the sediment load from Changjiang River have changed; the annual sediment discharge decreased from more than $400 \mathrm{Mt} \mathrm{yr}^{-1}$ before the 1980 s to below $150 \mathrm{Mt} \mathrm{yr}^{-1}$ after 2003 (Gao and Wang, 2008; Yang et al., 2014). Consequently, the net sediment flux of the first two of the above mentioned three transects decreased to 186 and $122 \mathrm{Mt} \mathrm{yr}^{-1}$, but that of the third one did not change much (Xie et al., 2017). Under such a condition, the sediment supply from the ZA to the adjacent sedimentary systems may become more important than that of the 1980 s.

Based on the sedimentary records of Cores SE1, SE2, DC2 and EC2005 (Zhang, 2014; $\mathrm{Xu}$ et al., 2012), the ${ }^{14} \mathrm{C}$ age profiles reveal a significant hiatus at $2 \mathrm{ka} \mathrm{BP}$ in the Holocene sequences, and only the upper sections of the deposits are related to the modern Changjiang River (Gao, 2013). A reasonable hypothesis is that the initial bathymetry of the Hangzhou Bay incised valley had a significant influence on the spatial distribution of the sediment discharge from both the Changjiang and Qiantang rivers. With a relatively small flux, the sediments supplied from the Qiantang River were almost entirely deposited to infill the incised valley, in the form of estuarine deposits, which is still an ongoing process nowadays. With the abundant sediment flux from the Changjiang River, rapid infilling took place in the early to middle Holocene periods, i.e., $5 \mathrm{ka} \mathrm{BP}$, and the sediments were deposited mainly in the lower reaches of the Qiantang River and the bay-head areas of the estuary. During the 5-2 ka BP, the sediment started to enter the present-day Changjiang River delta on a large scale; during the last 2000 years, the sediments of the Changjiang River began to escape from the estaurine waters, resulting in accumulation of fine-grained sediment in Hangzhou Bay and on the Zhejiang-Fujian inner shelf (Gao, 2013) (Figure 6c). With a relative smaller sediment flux compared with Changjiang River, the ZA, as mentioned above, has continued to supply sediments to its adjacent regions. If the life scale of the CRSS is taken as 6000 years (Hori et al., 2001), then the total sediment flux of the ZA reaches a quantity of $64.2 \mathrm{Gt}$. This amount equals to the total amount of sediment load from the Changjiang River for 
about 130 years. In particular, during the periods when the sediment supply from the Changjiang River was not large, i.e., 6-2 ka BP, the sediments from the ZA would represent a major source to its adjacent sedimentary systems. As such, the ZA sediment supply, when the Holocene temporal scale is taken into consideration, should have certain influence on the growth of the two sedimentary systems mentioned above.

To better understand the role of the ZA in the formulation of the CRSS during the Holocene, future research may focus on the following aspects. (1) Observations of sediment load at key locations in the ZA requires detailed gauging station records or measurements along key transects, against which the sediment flux predicted by existing models can be calibrated. (2) Numerical modeling of sediment transport should be carried out. At present, few numerical experiments associated with the effect of sediment input from the ZA have been undertaken to identify the relevant morphodynamic behavior of the Changjiang River sedimentary system. (3) Comparative studies on the role played by the archipelago in the formation of the sedimentary systems may be conducted for different systems. For instance, similar to the relationship between the ZA and Changjiang River, there are also many islands in the Zhujiang Estuary, from which it can be inferred that relatively large amount of sediment would have yielded during the Holocene. The different evolutionary stages of estuarine infilling, different distribution patterns of islands within the estuarine areas and different dispersal processes and sediment loads (Gao et al., 2015) make the Changjiang River and Zhujiang River sedimentary systems suitable comparable study areas for land-sea-islands interaction studies.

\section{Concluding remarks}

In this study we investigate the sediment supply from the Zhoushan Archipelago and its influence on the sedimentary systems associated with the Changjiang River. The models proposed by Milliman and Syvitski (1992), Mulder and Syvitski (1996), Syvitski et al., (2003) and Syvitski and Milliman (2007) were used to predict sediment load of the ZA. The estimated total sediment flux of the ZA ranges from $\sim 0.7$ to $26.5 \mathrm{Mt}^{-} \mathrm{yr}^{-1}$, with an average value of $10.7 \mathrm{Mt} \cdot \mathrm{yr}^{-1}$. The islands with a larger area or a maximum relief contribute greatly to the total flux of the ZA. This sediment load is an order of magnitude lower than those of the Changjiang and Choshui rivers, but has the same order of magnitude as those of the local Jiaojiang, Oujiang, Minjiang and Qiantang rivers. The ZA not only supplies sediments, but also serves as a geomorphic obstacle to influence the sediment transport into Hangzhou Bay and the Zhejiang-Fujian coastal seas. On a Holocene temporal scale, especially during 6-2 ka BP, the sediments from the ZA had an important effect on the Changjiang River sedimentary systems. Future research should focus on the observations of sediment load and numerical modeling of sediment transport at key locations in the ZA, and comparative studies on different large river sedimentary systems, in order to better understand the role played by an archipelago in the formulation of the sedimentary systems.

\section{References}

Baldacchino G, 2016. Archipelago Tourism: Policies and Practices. London: Routledge, 10-20.

Bianchi T S, Allison M A, 2009. Large-river delta-front estuaries as natural "Recorders" of global environmental 
change. Proceedings of the National Academy of Sciences, 106(20): 8085-8092.

Blackburn D C, Siler C D, Diesmos A C et al., 2013. An adaptive radiation of frogs in a Southeast Asian island archipelago. Evolution, 67(9): 2631-2646.

Bover P, Quintana J, Alcover J A, 2008. Three islands, three worlds: Paleogeography and evolution of the vertebrate fauna from the Balearic Islands. Quaternary International, 182(1): 135-144.

Carvajal-ndara S, Hendry A P, Emery N C et al., 2017. Habitat filtering not dispersal limitation shapes oceanic island floras: Species assembly of the Galápagos archipelago. Ecology Letters, 20(4): 495.

Chen C T A, 2009. Chemical and physical fronts in the Bohai, Yellow and East China seas. Journal of Marine Systems, 78(3): 394-410.

Chen J Y, Li C Z, Chongle Z et al., 1990. Geomorphological development and sedimentation in Qiantang Estuary and Hangzhou Bay. Journal of Coastal Research, 6(3): 559-572.

Dong Y F, 1991. Grain size features of bed material and sedimentary source in the Hangzhou Bay. Shanghai Geology, 12(3): 22-51. (in Chinese)

Fukuta A, Kamimura Y, Hori M et al., 2017. Offshore currents explain the discontinuity of a fish community in the seagrass bed along the Japanese archipelago. Fisheries Oceanography, 26(1): 65-68.

Jackson A M, Erdmann M V, Toha A H A et al., 2014. Phylogeography of commercial tuna and mackerel in the Indonesian Archipelago. Bulletin of Marine Science, 90(1): 471-492.

Kurniawan F, Adrianto L, Bengen D G et al., 2016. Vulnerability assessment of small islands to tourism: The case of the Marine Tourism Park of the Gili Matra Islands, Indonesia. Global Ecology and Conservation, 6(C): 308-326.

Gao S, 2013. Holocene shelf-coastal sedimentary systems associated with the Changjiang River: An overview. Acta Oceanologica Sinica, 32(12): 4-12.

Gao S, Collins M B, 2014. Holocene sedimentary systems on continental shelves. Marine Geology, 352(3): 268-294.

Gao S, Liu Y, Yang Y et al., 2015. Evolution status of the distal mud deposit associated with the Pearl River, northern South China Sea continental shelf. Journal of Asian Earth Sciences, 114: 562-573.

Gao S, Wang D, Yang Y et al., 2016. Holocene sedimentary systems on a broad continental shelf with abundant river input: Process-product relationships. Geological Society, London, Special Publications, 429(1): 223-259.

Gao S, Wang Y P, 2008. Changes in material fluxes from the Changjiang River and their implications on the adjoining continental shelf ecosystem. Continental Shelf Research, 28(12): 1490-1500.

Hanebuth T J, Lantzsch H, Nizou J, 2015. Mud depocenters on continental shelves: Appearance, initiation times, and growth dynamics. Geo-Marine Letters, 35(6): 487-503.

Hori K, Saito Y, Zhao Q et al., 2001. Sedimentary facies of the tide-dominated paleo-Changjiang (Yangtze) estuary during the last transgression. Marine Geology, 177(3): 331-351.

$\mathrm{Hu}$ R, Wu J, Li G et al., 2009. Characteristics of sediment transport in the Zhoushan Archipelago sea area. Acta Oceanologica Sinica, 28(5): 116-127.

Li Y Z, Cheng S L, Gu G C, 2002. Modern sedimentation environment in Qiqu Archipelago. Shanghai Geology, 23(2): 11-16. (in Chinese)

Lin C M, Zhuo H C, Gao S, 2005. Sedimentary facies and evolution in the Qiantang River incised valley, eastern China. Marine Geology, 219(4): 235-259.

Liu J P, Li A C, Xu K H et al., 2006. Sedimentary features of the Yangtze River-derived along-shelf clinoform deposit in the East China Sea. Continental Shelf Research, 26(17): 2141-2156.

Liu J P, Liu C S, Xu K H et al., 2008. Flux and fate of small mountainous rivers derived sediments into the Taiwan Strait. Marine Geology, 256(1): 65-76.

Liu P, Yu Y, Liu C, 1991. Studies on the situation of pollution and countermeasures of control of the oceanic environment in Zhoushan fishing ground: The largest fishing ground in China. Marine Pollution Bulletin, 23: 281-288.

Liu S, Liu Y, Yang G et al., 2012. Distribution of major and trace elements in surface sediments of Hangzhou Bay in China. Acta Oceanologica Sinica, 31(4): 89-100.

Milliman J D, Sheng H T, Yang Z S et al., 1985. Transport and deposition of river sediment in the Changjiang estuary and adjacent continental shelf. Continental Shelf Research, 4(1/2): 37-45.

Milliman J D, Syvitski J P, 1992. Geomorphic/tectonic control of sediment discharge to the ocean: The importance of small mountainous rivers. The Journal of Geology, 100(5): 525-544.

Milliman J D, Farnsworth K L, 2013. River Discharge to the Coastal Ocean: A Global Synthesis. London: Cam- 
bridge University Press, 12-35.

Milliman J D, Farnsworth K L, Albertin C S, 1999. Flux and fate of fluvial sediments leaving large islands in the East Indies. Journal of Sea Research, 41(1/2): 97-107.

Mountz A, 2015. Invisibility and the securitization of migration shaping publics through border enforcement on islands. Cultural Politics, 11(2): 184-200.

Mulder T, Syvitski J P M, 1996. Climatic and morphologic relationships of rivers: Implications of sea-level fluctuations on river loads. The Journal of Geology, 104(5): 509-523.

Nienhuis J H, Ashton A D, Giosan L, 2015. What makes a delta wave-dominated? Geology, 43(6): 511-514.

Ogasawara K, 1994. Neogene paleogeography and marine climate of the Japanese Islands based on shallow-marine molluscs. Palaeogeography, Palaeoclimatology, Palaeoecology, 108(3/4): 335-351.

Palestini L L, 2016. The territorial and maritime dispute (Nicaragua v. Colombia): On Territorial Sovereignty and the International Court of Justice's "Failure to Rule" on the geographical scope of the Archipelago of San Andrés. The Law \& Practice of International Courts and Tribunals, 15(1): 56-80.

Pan C, Huang W, 2010. Numerical modeling of suspended sediment transport affected by tidal bore in Qiantang Estuary. Journal of Coastal Research, 26(6): 1123-1132.

Sha X G, 2007. Sedimentary characteristics and provenance of the mud sediments in the Zhoushan area of the East China Sea [D]. Changchun: Jilin University, 165. (in Chinese)

Stankowski S, Johnson M S, 2014. Biogeographic discordance of molecular phylogenetic and phenotypic variation in a continental archipelago radiation of land snails. BMC Evolutionary Biology, 14(1): 2.

Su J L, Wang K S, 1989. Changjiang river plume and suspended sediment transport in Hangzhou Bay. Continental Shelf Research, 9(1): 93-111.

Sun Y, Huang W S, 1984. The siltation process and silt sources of the Zhejiang coast. Donghai Marine Science, 2(4): 34-42. (in Chinese)

Syvitski J P, Peckham S D, Hilberman R et al., 2003. Predicting the terrestrial flux of sediment to the global ocean: a planetary perspective. Sedimentary Geology, 162(1): 5-24.

Syvitski J P M, Milliman J D, 2007. Geology, geography, and human's battle for dominance over the delivery of fluvial sediment to the coastal ocean. Journal of Geology, 115(1): 1-19.

Wang Q, Yu C D, 1992. Development, use and management of the Zhoushan fishing ground, China. Naga, the ICLARM Quarterly, 15(1): 11-15.

Wang Y B, Wang Y, 2016. Estimating catches with automatic identification system (AIS) data: A case study of single otter trawl in Zhoushan fishing ground, China. Iranian Journal of Fisheries Sciences, 15(1): 75-90.

Whittaker R J, Fernández-Palacios J M, 2007. Island Biogeography: Ecology, Evolution, and Conservation. Cambridge: Oxford University Press, 16-90.

Wu H L, Shen H T, Yan Y X et al., 2006. Preliminary study on sediment flux into the sea from Changjiang Estuary. Journal of Sediment Research, 12: 6-13.

Xia X M, 2014. China’s Islands: Zhejiang (Volume II: Zhoushan Archipelago). Beijing: China Ocean Press, 9-929. (in Chinese)

Xie D F, Gao S, Wang Z B et al., 2013. Numerical modeling of tidal currents, sediment transport and morphological evolution in Hangzhou Bay, China. International Journal of Sediment Research, 28(3): 316-328.

Xie D F, Pan C H, Wu X G et al., 2017. The variations of sediment transport patterns in the outer Changjiang Estuary and Hangzhou Bay over the last 30 years. Journal of Geophysical Research: Oceans, 122: 2999-3020. doi: 10.1002/2016JC012264.

Xu K, Li A, Liu J P et al., 2012. Provenance, structure, and formation of the mud wedge along inner continental shelf of the East China Sea: A synthesis of the Yangtze dispersal system. Marine Geology, 291: 176-191.

Yan Q S, Xiang L S, Zhang G D et al., 1981. Modern coastal sediments of Putuo Island, Zhoushan Archipelago. Acta Geologica Sinica, 55(3): 205-214. (in Chinese)

Yang S L, Milliman J D, Xu K H et al., 2014. Downstream sedimentary and geomorphic impacts of the Three Gorges Dam on the Yangtze River. Earth-Science Reviews, 138: 469-486.

Yang Y P, Zhang M J, Li Y T et al., 2015. The variations of suspended sediment concentration in Yangtze River Estuary. Journal of Hydrodynamics, Ser. B, 27(6): 845-856.

Zhang Q L, Wang F, Zhao W H et al., 2007. Seasonal characteristics in the water masses in Zhoushan Fishing Ground and adjacent region. Acta Oceanologica Sinica, 29(5): 1-9.

Zhang X, Lin C M, Dalrymple R W et al., 2014. Facies architecture and depositional model of a macrotidal incised-valley succession (Qiantang River estuary, eastern China), and differences from other macrotidal systems. Geological Society of America Bulletin, 126(3/4): 499-522. 